J. Lake Sci. (湖泊科学), 2013, 25(4): 455-462

http: //www. jlakes. org. E-mail : jlakes@niglas.ac.cn

(C) 2013 by Journal of Lake Sciences

\title{
水动力条件对水体富营养化的影响”
}

\author{
梁培瑜 ${ }^{1,2}$, 王 烜 $^{1,2 * *}$, 马芳冰 ${ }^{1,2}$ \\ ( 1 : 北京师范大学环境学院水沙科学教育部重点实验室, 北京 100875) \\ (2: 北京师范大学环境学院水环境模拟国家重点实验室, 北京 100875)
}

\begin{abstract}
摘 要: 水动力条件是影响水体富营养化状态和进程的主要自然因素. 研究水动力条件对水体富营养化的影响对于水体 富营养化模拟、预测和控制具有十分重要的意义. 水动力条件能直接作用于水华藻类细胞, 影响其生长繁殖与种间竞争, 同时改变水体环境及营养盐的状况. 其中, 流速不仅对藻类的生长聚集与分布具有十分明显的影响, 同时还能影响水体 营养物质与优势藻的种类;流量则主要通过单位时间内水量的变化影响水体富营养化的发生与消亡; 水体扰动直接作用 于水体中藻类细胞与藻团, 加强藻类的聚集, 同时影响营养物质的混合与运移, 从而使水体富营养化得以发生并持续. 本 文综述了流速、流量和水体扰动等水动力因子对水体富营养化的影响研究, 并对其未来的研究方向进行展望, 最后指出: 不同水动力条件对营养盐存在形态、藻类生长及水体富营养化状态的影响机理和水动力条件对水体富营养化影响的滞 后性规律与临界值研究有待进一步加强.
\end{abstract}

关键词: 水动力条件;富营养化;流速;流量;水体扰动;藻类

\section{Effect of hydrodynamic conditions on water eutrophication: A review}

\author{
LIANG Peiyu ${ }^{1,2}$, WANG Xuan ${ }^{1,2} \&$ MA Fangbing ${ }^{1,2}$ \\ (1: Key Laboratory for Water and Sediment Sciences of Ministry of Education, School of Environment, Beijing Normal Univer- \\ sity, Beijing 100875 , P. R. China) \\ (2: State Key Laboratory of Water Environment Simulation, School of Environment, Beijing Normal University, Beijing \\ 100875 , P. R. China)
}

\begin{abstract}
Hydrodynamic conditions, including the flow velocity, discharge and water disturbances, play a key role in the occurrence, development, continuation and extinction of eutrophication. In order to prevent and control eutrophication, it is vital to study the influence of hydrodynamic conditions on eutrophication. Hydrodynamic conditions can not only affect the growth and interspecific competition of algae, but also change natural environment and nutrient loads of the water body. More details are as follows. (1) The flow velocity has a very significant effect on algae aggregation and distribution, as well as nutrients and the dominant algae. It is also found that there is an adaption period of the growth of algae biomass to the change of the flow velocity. (2) Discharge makes an effect on eutrophication mainly by altering the flow velocity and water quantity. (3) Water disturbance, which mainly originating from wind and tide et al, directly acts on algae cells and groups in strengthening the aggregation of algae, as well as influences the mixture and transportation of nutrients in vertical and horizontal directions. Reynolds Number and the type of water circulation are also regarded as hydrodynamic factors, which can make influence to eutrophication. At present, the study of hydrodynamic conditions' impacts on eutrophication is still in the stage of qualitative research. Some key issues, such as the influence on nutrients, the law of hysteretic nature and critical value of hydrodynamic conditions, still need further study.
\end{abstract}

Keywords: Hydrodynamic conditions; eutrophication; velocity; discharge; water disturbance; algae

水体富营养化问题是全球性的水环境问题之一. 产生水体富营养化的主要原因是水体中藻类异常增

* 国家科技支撑计划课题项目 (2011BAC12B02)、国家水体污染控制与治理科技重大专项项目 (2008ZX07209-009) 和 国家自然科学基金优秀创新群体项目 (51121003) 联合资助. 2012-09-28 收稿;2013-01-04 收修改稿. 梁培瑜, 男,1990 年生,硕士研究生;E-mail:lpyjx1990@ mail. bnu. edu. cn.

** 通信作者;E-mail:wangx@ bnu. edu.cn. 
殖, 而水华藻类动态变化受其内部生理特征和外部驱动因素的综合作用. 影响藻类生长的外部因素不仅包 括物理、化学和生物等因素, 如阳光、营养盐类、透明度、水温和 $\mathrm{pH}$ 值等, 同时也包括水体中的水动力条件, 如流速 ${ }^{[1-2]}$ 、流量 ${ }^{\left[{ }^{3}\right]}$ 和水体扰动 ${ }^{[4-5]}$ 等. 水体中的水动力条件与藻类的生长繁殖有着密切的关系, 它们不仅能 直接作用于藻类, 还对水体中营养盐状况与水温层结构有明显的影响, 并间接作用于水体富营养化, 因而是 影响水体富营养化状态和进程的主要自然因素. 在河流与河口, 当流速较缓、流量适中的时候, 浮游植物在 适宜的营养条件下密度往往会显著增加, 而在流速大、流量大的水体中藻类密度较小; 在湖泊水库, 由风场 所形成的扰动不仅会导致局部出现大量的水藻, 且能发现藻类生长快于水体静止的情况. 大量的研究表明, 水动力条件影响着藻类的生长, 优势种演替、聚集, 同时对各种营养盐、污染物质、泥沙与沉积物的形态、传 输和分布产生影响 ${ }^{[6-7]}$, 从而对水华暴发起着重要的作用. 除此之外, 水流雷诺数、剪切力及水体循环形式等 水动力因子也会对浮游藻类的生长与繁殖产生影响. 研究水动力条件对水体富营养化的影响对于水体富营 养化模拟、预测和防治具有十分重要的意义. 本文对流速、流量、水体扰动等水动力因子对水体富营养化的 影响研究进行综述,并对其未来的研究方向进行展望.

\section{1 水动力因子对水体富营养化的影响}

不论是何种类型的流动水体, 均为一定流速、流量下的热、质的载体, 同时也存在因水体流场变化所造 成的扰动. 各种水动力因子的协同作用, 共同影响着藻类生存的水体环境、营养盐的状况以及藻类的生长聚 集、分布乃至藻类种群的自然选择, 进而在水体富营养化的发生、发展与消亡过程中发挥关键作用. 对于不 同的水体类型, 由于发生富营养化的机理与水体的营养状况不同, 各种水动力因子发生作用的方式和效果 也各异.

\section{1 流速的影响}

流速是表征水动力条件最基本、最直观的因子, 它对藻类的生长、聚集与分布具有十分明显的影响. 目 前的研究多采用室内模拟的手段, 在控制其它条件一定的情况下, 研究不同流速对单一藻类的影响. 赵颖 等 ${ }^{[8]}$ 通过室内模拟得出, 在其它条件满足藻类生长需求的条件下, 流速、温度对藻类生长均有一定的影响, 其中流速的影响作用更为显著. 李林等 ${ }^{[9]}$ 与曹巧丽 ${ }^{[10]}$ 基于实验得出不同的水流流速对微囊藻生长的影响直 接表现为, 改变了藻类的生长周期和比增长率, 最终影响到藻类的最大生物量. 不少野外实验也表明水流作 用对水体中水华藻类的发生及富营养化有明显的影响. 任健等 ${ }^{[11]}$ 与高吴东等 ${ }^{[12]}$ 分别对水华频发的太湖和 烟台四十里湾海域进行研究, 发现水流条件是研究区内蓝藻暴发的主要诱导因素之一, 合适的流速环境能 给水华与赤潮的发生营造有利的外部环境. Acuna 等 ${ }^{[13]}$ 与 Mitrovic 等 ${ }^{[14]}$ 分别对南美河流 (Pampean stream) 与达令河 (Darling) 进行研究指出, 较缓的流速能促进悬浮藻类的生长, 而过高的流速则抑制悬浮藻类的生 长,并且较大流速能有效地阻止水华的形成与发展,消除已经形成的水华.

流速能使原来悬浮质中的一些磷、氮营养元素在机械等理化和生物作用下, 释放到水体中, 从而影响藻 类变化, 最终对水体富营养过程与水华的暴发产生影响. Finlay 等 ${ }^{[15]}$ 从生态角度认为流速改变河流食物网 的能流状况, 并影响藻类对碳的吸收. Koch ${ }^{[16]}$ 以摩阻流速作为研究因子, 得出较大的摩阻流速 $(>1.0 \mathrm{~cm} / \mathrm{s})$ 对石莼的生长不利, 而当摩阻流速为 $0 \sim 1.0 \mathrm{~cm} / \mathrm{s}$ 时, 水体中能形成充足的碳源, 从而促进石莼藻类的生长. 流速条件不仅对单一藻类的生长产生影响, 而且还能改变水体中藻类的群落及优势种的类型. 流速运动促 使水体中浮游藻类向水流方向运移, 影响藻类的混合, 甚至对固着藻类产生冲刷作用, 从而影响藻类个体的 存在、生长与藻类群落结构. Sherman 等 ${ }^{[17]}$ 通过实验研究发现, 流速影响水体温度层的结构从而间接影响藻 类种群, 并对直链藻与项圈藻 2 种藻类的优势性产生影响. Mcintire 等 ${ }^{[18]}$ 在实验室中研究流速对固着藻类组 成的影响, 指出在较快的流速中硅藻一般成为优势种; 而在较慢的水流环境中, 则毛枝藻、鞘藻和黄丝藻常 常变为优势种. 藻类对水流流速有一个适应范围, 且不同藻类的适应范围与适应度并不一致. 在一定流速状 态下, 较适应的藻种能取得较好地生长并成为优势种. 有研究认为, 优势藻类与水体温度层的结构有关, 而 温度层的持续与稳定又受到河流流速的影响, 因此河流流速通过影响水体的温度层结构间接影响藻类的 生长 ${ }^{[19]}$.

大量研究表明, 适宜的水流有利于藻类的生长和繁殖, 因为水的运动使藻类不断地得到新营养物质的供 
应. 然而, 较大的水流流速会导致较大的剪应力和切变速率, 易导致藻类细胞的破坏 ${ }^{[20]}$. 因此, 水流流速对藻类 生长与水华的影响存在一个最适值, 即临界流速. 王华等 ${ }^{[21]}$ 对微囊藻的室内实验得到在设定的环境条件下 微囊藻的细胞增长率与流速的关系, 可看出环境中流速低于或超过某个值都不利于微囊藻的生长繁殖 (图 1). Long 等 ${ }^{[22]}$ 通过建立模型对叶绿素 a 浓度的时间与空间分布进行预测分析, 认为 $0.04 \mathrm{~m} / \mathrm{s}$ 是浮游藻类生 长的最佳流速. Olivier 等 ${ }^{[23]}$ 观测到松藻的存在与存活受不同波浪和水流的影响, 认为水流作用的水力拖曳 力对松藻的形态与存活有一个最大影响值, 并通过室内实验得到松藻生存的临界流速为 $0.5 \mathrm{~m} / \mathrm{s}$. Mitrovic 等 ${ }^{[19]}$ 通过在淡水达令河测量得到, 项圈藻大量暴发的临界流速为 $0.05 \mathrm{~m} / \mathrm{s}$. 研究者在不同区域得出的临界 流速并不相同, 而藻类对流速的适应性也存在差异, 同时有研究认为藻类生长的临界流速值在各种水体营 养条件下也不尽相同 ${ }^{[24]}$. 对于临界流速的存在, 大多是基于特定区域的监测数据推断得出, 由于研究区域和 藻类种属较分散, 同时临界流速影响因素的机理研究还未深人展开, 使得相关结论缺乏可移植性. 此外, 王 婷婷等 ${ }^{[25]}$ 认为流速影响铜绿微囊藻各个生长时期的长短, 且铜绿微囊藻对流速的适应需要一定的时间 (图 $2)$. 藻类对外界环境的改变有一个适应阶段, 最终表现为流速对藻类生长的影响具有滞后性, 这种滞后性表 现在藻类的最大生物量与最大比增长率达到稳定的时间延迟 ${ }^{[26]}$.

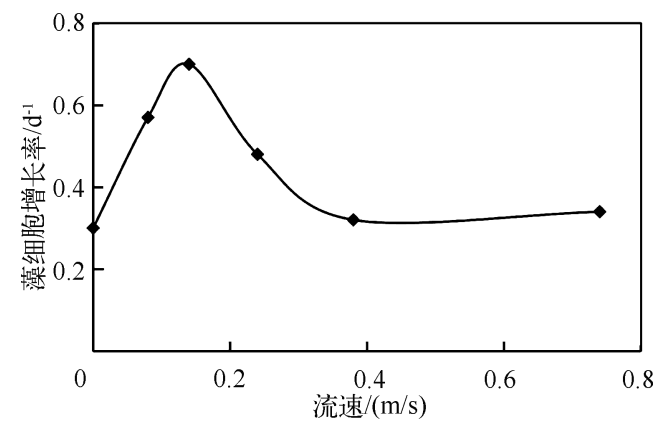

图 1 水体流速与铜绿微囊藻细胞增长率相关曲线 ${ }^{[21]}$

Fig. 1 The relation curve between velocity and Microcystis aeruginosa cell growth rate ${ }^{[21]}$

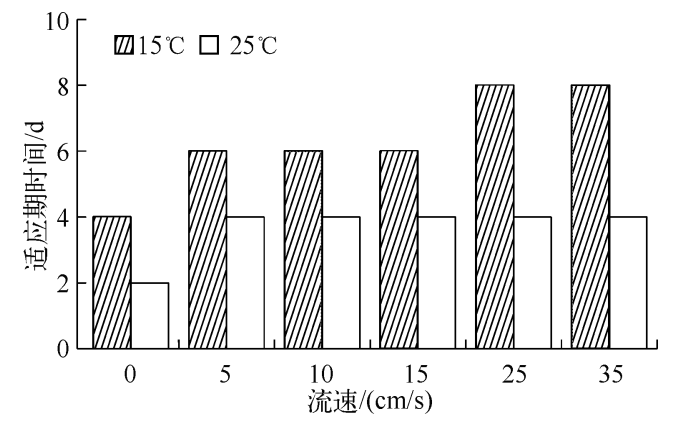

图 2 铜绿微囊藻在不同流速水体中适应期 ${ }^{[25]}$

Fig. 2 The adaption period of Microcystis aeruginosa to different water velocities ${ }^{[25]}$

也有学者通过统计分析与模型得到藻类与水体流速的定量关系, 包括藻类浓度与流速的关系式 $a=$ $m \cdot \exp (k / v)^{[27]}, y=34.042-293.725 u+821.265 u^{2}-603.45 u^{3[28]}$, 藻类生长速率中引入流速影响函数式 $f(u)=v^{r u}[29]$, 对叶绿素 $\mathrm{a}$ 浓度与藻类关系进行模拟预测的二维非稳态藻类生长模型 ${ }^{[21-22]}$, 水动力-浮游植物 耦合模型 ${ }^{[30]}$ 等. 这些定量公式主要是通过曲线拟合得到, 或基于水动力模型与藻类生长模型的耦合并在模 型中加人流速参数或者流量影响因子式等. 目前从藻类与水体流速的定量研究中得到大量经验公式, 同时 在相关模型中流速也作为水动力参数之一, 但对流速与藻类之间的定量关系描述并不成熟. 为了更好地描 述和量化流速变化对藻类生长的外部环境和自身发展的影响, 以便为水体富营养化防治提供科学依据, 需 要进一步从机理层面研究流速对藻类的影响和作用机制.

\section{2 流量的影响}

流量作为水动力条件的因子之一, 也是影响水体富营养化的重要因素之一. Ha 等 ${ }^{[2]}$ 和 Jeong 等 ${ }^{[31]}$ 通过 在河流中进行长期观测, 认为流量的输人影响河流中浮游藻类的生物量, 同时也是引起河流中水华现象的 主要外部原因之一. Lung 等 ${ }^{[3]}$ 在 Neuse 河建立数学模型对 4 种藻类进行模拟, 结果得出淡水流量的输人对 水华产生重要影响. 流量对水体有一个稀释作用, 从而对水体营养盐浓度产生影响; 同时流量使水体营养盐 的交换作用加强, 从而影响水体中藻类的生长环境. 林卫青等 ${ }^{[22]}$ 利用生态动力学模型预测表明水体停留时 间的长短是决定藻类是否过度繁殖的重要条件, 加大引水流量、减少淀山湖水体停留时间是有效控制蓝藻 水华的重要途径. 龙天渝等 ${ }^{[33}$ 对嘉陵江重庆主城段的藻类生长情况进行了研究,结果表明大坝上游的来流 量和大坝泄水量均较小时, 藻类密度平均值和藻类质量净增量最大; 而当来流量增大时河段的藻类生长受 到抑制, 且消亡率大于生长率. 
流量对水体富营养化的影响同样有一个范围,过大的流量所产生的冲刷与稀释作用使藻类不能集中暴发,而 过小的流量往往不能满足水华暴发的条件. Acs 等 ${ }^{[34]}$ 对多瑙河 (Danube) 的研究表明, 低流量 (100 400 $\mathrm{m}^{3} / \mathrm{s}$ ) 有 利于硅藻的生长, 而过大的流量对硅藻的生长有抑制作用. 流量对水体富营养化的制约作用十分显著, 谢平 等 ${ }^{[35]}$ 通过富营养化动力学模型研究得出, 在营养条件已满足藻类生长需求的情况下, 流量、流速是制约汉江 水华发生的关键因子; 并提出当流量高于 $500 \mathrm{~m}^{3} / \mathrm{s}$ 时, 可有效防止汉江水华发生. 虽然流量越大对水体富营 养化的抑制作用越明显, 但在当前水资源十分紧缺的情况下, 使用过大的流量来防止水体富营养化并不现 实, 因此流量对水体富营养化影响的研究主要集中于一个有效值如环境流量 (environmental flows ${ }^{[36]}$ 上.

\section{3 水体扰动的影响}

水体扰动是水动力条件的重要因子, 同时影响着水体环境的稳定, 对藻类生长与水体富营养化的水体 环境有着必然的影响. 水体的扰动主要来源于风场 ${ }^{[37]}$ 、潮汐 ${ }^{[38]}$ 等的扰动作用, 水体中扰动场的存在能为藻 类的生长繁殖提供一定的环境, 适度的水体扰动往往能降低藻细胞周围代谢产物的浓度, 促进水体藻类的 生长, 最终导致水华的暴发. Kriss 等 ${ }^{[39]}$ 对小范围扰动进行了试验并通过多元统计分析得到, 浮游植物生物 量及叶绿素 $\mathrm{a}$ 浓度与扰动强度呈正相关. 蔡卓平等 ${ }^{[40]}$ 的研究表明风浪扰动能显著地促进藻类的细胞增殖, 且其最大生长速率与生物量均大于静止培养下的值.

水体扰动能直接作用于水体中的藻类细胞与藻团, 加强藻类的聚集, 改变形成水华的生物学条件, 并影 响营养物质的混合与运移, 从而促进或削弱水体富营养化. 大风浪扰动能引起浅水湖泊中颗粒态和溶解态 营养盐浓度的迅速提高, 并为水华蓝藻的快速生长提供大量可直接利用或酶解的营养盐 ${ }^{[41]}$. 水体垂向扰动 有助于藻细胞对水分和营养物质的吸收并增强悬浮物的混合, 进而促进水华藻细胞的生长与藻类的繁殖, 同时能加强藻细胞的悬浮, 防止细胞沉降到底部, 进而促进藻细胞的密度增长和聚集 ${ }^{[42]}$. 在一定强度的风浪 下, 水体的垂直混合会引起初级生产力的垂直变化, 影响浮游藻类的组成及生长并抑制藻类的增长和聚集, 从而削弱水华 ${ }^{[43]}$. 水体横向扰动会使水体中藻类产生定向的漂移与聚集. Webster ${ }^{[44]}$ 、朱永春等 ${ }^{[45]}$ 通过模型 模拟在风场所形成的水体扰动下浮游藻类密度与分布得到, 藻类在湖泊中的分布随风场而漂移. 对太湖的 研究发现, 太湖高频率的东南东风和东南风, 使得蓝藻向太湖的中西部和北部漂移居多, 从而导致 2007 年 太湖蓝藻水华暴发的区域大部分位于太湖蓝藻密度较大的中西部和北部地区 ${ }^{[46]}$.

水体扰动是藻类种间竞争的选择推动力之一, 通常认为生物的生长速率与扰动具有正相关关系, 小规 模的水流扰动有利于藻类的生长和繁殖. 减少光照波动, 增加藻细胞与周围介质的营养、代谢产物的交换速 率, 可使藻类不断得到新的营养物质供应, 从而增加生产力和光合作用效率 ${ }^{[20]}$. 然而, 不同扰动强度下不同 藻类的生物量不同, 生长速率也不同. 李冬梅等 ${ }^{[47]}$ 在室内实验研究发现, 扰动对中肋骨条藻、具齿原甲藻等 10 个藻种生长存在不同影响, 10 种藻类对扰动表现出不同的生长反应. 颜润润等 ${ }^{[48]}$ 设置 5 个扰动强度对铜 锈微囊藻和斜生栅藻进行实验, 研究表明扰动为 150 转/ $\mathrm{min}$ 时微囊藻的比增长率小于栅藻, 其它扰动强度 下微囊藻的比增长率均大于栅藻. Mischke 等 ${ }^{[49]}$ 研究了德国 2 个相似的超富营养浅水湖泊中蓝藻对扰动的 反应, 发现在蓝藻出现优势的夏季, 受风扰动影响小的湖泊中优势种为湖生蓝丝藻, 而受风扰动影响大的湖 泊中优势种则为阿氏浮丝藻. 藻类细胞大小、形态和生活方式等对水体扰动的适应性均有差异, 且不同藻类 对水体扰动的适应范围也有不同, 一定的水体扰动能促进某些藻类的生长而抑制其它藻类的生长, 进而改 变水体中的藻种.

扰动不仅有助于藻细胞对营养物质的吸收, 而且能够提高藻细胞对营养物质的利用率. 藻细胞的最大 生长情况只在某一最适水体扰动下才能得到. 颜润润等 ${ }^{[50]}$ 的实验表明, 在太湖 $4.0 \mathrm{~m} / \mathrm{s}$ 的风速所产生的扰 动强度最利于铜绿微囊藻的生长. $\mathrm{Li}$ 等 ${ }^{[51]}$ 将流量的变化作为一个扰动, 通过对三峡水库支流澎溪河的观测 得到,当日流量变化为 $19.46 \mathrm{~m}^{3} / \mathrm{s}$ 时所产生的扰动为最适流量扰动.

目前有关水体扰动对富营养化影响的表示方法主要包括风场大小、实验振动强度及流量变化值等间接 方法, 而并未形成水体扰动强度的统一表示方法. 水体扰动临界值是控制藻类生长和水体富营养化的关键 数据,加强对水体扰动的表示方法与临界值的研究十分必要.

\section{4 其它水动力因子的影响}

水动力条件不仅仅体现在流速、流量与水体扰动 3 个因子上, 国内外很多学者从不同的角度, 对水动力 
条件的其它表征因子进行研究. 王云中等 ${ }^{[52]}$ 从静止、水循环和泥循环 3 种情景下对藻类演替进行研究认为, 水循环引起 TP 浓度减少及蓝藻聚集状态的破坏, 导致了藻类的生长明显减缓, 但也使水体中优势种的演化 过程变得复杂; 泥循环导致水体 $\mathrm{TP}$ 浓度的极大减少及浊度的极大增加, 从而抑制藻类的生长. Midhat 等 $^{[53]}$ 通过实验研究剪切流对栅藻生长的影响得到, 藻类最大生长率的临界雷诺数为 2500 ; 同时从能量耗散的角 度分析了藻团在不同剪切力下的分布规律, 结果表明当剪切力为 $62.3 \times 10^{-3} \mathrm{~m}^{2} / \mathrm{s}$ 时藻团密度达到最大, 而 当剪切力达到 $181 \times 10^{-3} \mathrm{~m}^{2} / \mathrm{s}$ 时藻团细胞则会被破坏.

营养盐的存在是水体富营养化得以发生并持续的关键要素. 研究表明水动力条件能影响水体中营养盐 的分布与存在形式 ${ }^{[54]}$, 也能改变水体理化环境因子如悬浮物、透明度、 $\mathrm{pH}$ 和营养盐浓度 ${ }^{[55-56]}$, 进而影响水体 富营养化. 彭进平等 ${ }^{[57]}$ 以太湖为对象进行模拟实验表明,随着水体流速从 $0 \mathrm{~cm} / \mathrm{s}$ 增加到 $60 \mathrm{~cm} / \mathrm{s}$, 水体中 $\mathrm{TP}$ 质量浓度的变化出现下降期、上升期和突增期 3 个时期; 在低流速下,水体的 TP 主要以溶解性磷的形式存 在, 且质量浓度可达 $87 \%$, 对水体环境不利. 水动力条件还能影响水体环境, 如水体边界层的厚度, 从而影响 向细胞提供营养盐的供应速度, 即影响细胞对营养盐的吸收速率 ${ }^{[58]}$, 而水动力条件如何影响藻类对营养盐 吸收的研究并不多,其作用机理尚不十分清楚.

\section{2 讨论}

各种水动力条件对水体富营养化的影响总结如表 1 所示. 需要特别注意的是, 水体富营养化受各个水 动力因子的作用并不是孤立存在、简单叠加的关系, 它们之间相互联系、相互影响, 具体分析如下: (1) 流速 与流量密切相关. 在物理量的表征上, 流速与流量可通过过水面积进行转换, 当面积一定时, 纵向流速与流 量一般呈正相关. 然而, 由于水体边界条件不同, 湖泊水库和河渠的水动力条件下藻类生长规律存在明显差 异. 在河渠中, 水流的流速直接决定了流态 (层流、过渡流、湍流), 而流态的变化造成水流剪应力的变化及藻 类对水流剪应力的响应发生变化 ${ }^{[20]}$, 因此流速是这类水体发生富营养化的决定性水动力因子. 而在营养盐 相对充足、水流缓慢及适宜的气候条件下,湖泊、水库水体发生 “水华”现象远多于河流. 此时, 流量的输人促 进了营养物稀释与混合, 因此水流的流量大小对营造水体富营养化的外部环境、改变藻类的生物量具有至 关重要的作用. (2) 扰动的作用. 不论湖泊水库还是河渠,均存在流场变化所造成的扰动. 在河渠中,水流的 主体从上游向下游单向流动, 藻类在水域中按照主流方向迁移, 并在空间上扩散沉降, 故在低扰动下水动力 对藻类的聚集作用和对其生长的促进作用不容易表现出来 ${ }^{[59]}$. 对于湖泊而言, 水动力条件主要由湖水表面 的风扰动而产生,水体流动结构主要是以平面和立面环流的形式存在, 风通过摩擦作用将动能传递给水体 后,会产生波动和流动,单纯的波动流速或水流流速都不能代表波、流共存的特性. 因此湖泊的水动力条件 不同于河渠, 以往研究中关于流速对藻类生长影响的规律不完全适用于湖库, 水体扰动对富营养化影响更 显著. 因此, 对于不同的水体类型, 发生富营养化的机理和关键水动力因子不同, 需要结合水体特点研究水 动力因子的作用机制.

表 1 水动力条件对水体富营养化的影响

Tab. 1 Influence of hydrodynamic conditions on water eutrophication

\begin{tabular}{|c|c|c|c|c|}
\hline 水动力因子 & 表征因子 & 产生作用 & 影响方面 & 研究特点 \\
\hline 流速 & 流速, 摩阻流速 & $\begin{array}{l}\text { 水平迁移, } \\
\text { 混合作用 }\end{array}$ & $\begin{array}{l}\text { 水体环境, 藻类生长周期、增长率, } \\
\text { 藻类密度, 优势藻种类型等 }\end{array}$ & $\begin{array}{l}\text { 室内研究为主,研究区域集中 } \\
\text { 于河流 }\end{array}$ \\
\hline 流量 & 流量, 水力停留时间 & $\begin{array}{l}\text { 稀释作用, } \\
\text { 交换作用 }\end{array}$ & 水体环境, 藻类生长, 藻类密度等 & $\begin{array}{l}\text { 观测分析与模拟研究为主,研 } \\
\text { 究区域为河流、水库与湖泊 }\end{array}$ \\
\hline 水体扰动 & $\begin{array}{l}\text { 风场强度,潮汐强度, } \\
\text { 振动强度,摩阻流速 }\end{array}$ & $\begin{array}{l}\text { 垂向混合, } \\
\text { 水平迁移 }\end{array}$ & $\begin{array}{l}\text { 水体环境, 藻类聚集, 营养物的运 } \\
\text { 移、混合与吸收效率, 优势藻种等 }\end{array}$ & $\begin{array}{l}\text { 室内研究为主,研究区域多为 } \\
\text { 湖泊、水库与海湾等 }\end{array}$ \\
\hline 其它 & 雷诺数,水体循环类型 & $\begin{array}{l}\text { 剪切作用, } \\
\text { 混合作用 }\end{array}$ & 水体环境, 藻类细胞, 营养盐等 & - \\
\hline
\end{tabular}

实际湖体中, 藻类生长及水华的变化是多种因素的叠加效应. 水动力条件不仅使水体中本身的营养物 
质充分被藻类利用,还会通过水体摚动使底泥或悬浮物中的一些氮、磷营养元素释放到水体中. 水体的营养 条件亦会影响水动力因子作用的效果, 如低、中营养条件下, 藻细胞的生长易受扰动影响, 而高营养条件下, 藻类受扰动影响不大, 扰动却可以改变由营养水平不同所引起的藻类生长的差异 ${ }^{[20]}$. 因此, 需要综合考虑各 种外界因素对水体富营养化的影响.

藻类对水体温度、水体结构等水体环境及营养盐状况有一定的耐受程度 ${ }^{[60-61]}$, 而水动力因子均对水体 温度层与水体结构产生直接影响, 同时影响水体营养物质的混合、迁移与悬浮物的吸附、解吸附作用, 使得 水体藻类的生长与繁殖对水动力条件存在着同样的耐受性, 在相关研究时常能体现在水动力条件对藻类生 长与富营养发生的临界值上. 研究不同水体与营养条件下富营养化发生的机理, 明确水动力因子的临界值, 对防治与控制水体富营养化有十分实用的价值.

由于水体富营养化本身是一个过程, 藻类的生长存在不同的阶段, 使得水动力条件对水体富营养化的 影响存在一个滞后效应. 这种滞后效应主要源自于水动力因子对水体环境的改变需要一个过程, 同时水华 藻类对水体环境的适应也存在一个过程. 目前有相关研究的报道, 但并未对水体富营养化的这种滞后响应 的规律进行深人探讨. 弄清这种滞后规律能进一步精确地预测水华的暴发.

\section{3 结语与展望}

水动力条件对富营养化的影响不但体现在对水体富营养化藻类的影响上, 而且体现在对水体富营养化 存在与发展的水体环境的影响上. 流速、流量与水体扰动是水动力条件对水体富营养化影响的主要因子. 流 速与水体扰动不仅能通过对水华藻类的生长、聚集与藻类结构产生直接影响, 而且对水体中营养盐的运动 与混合产生影响, 进而影响水体富营养化的生成、发展、持续与消亡. 而流量因子则从水量与流速上对水体 富营养化的发生与持续产生影响. 同时, 水动力条件对水体藻类生长与富营养化程度的影响并不是一个简 单的线性关系, 而是存在一个临界值, 高于或者低于这个值都会对藻类生长与富营养化起到抑制作用.

目前水动力条件对水体富营养化的影响研究虽然已取得了一定成果, 但是水动力条件对水体富营养化 产生影响的定量关系尚不明确, 同时这种影响往往还有一个滞后过程, 加之水体富营养化受到水温、营养 盐、泥沙等其它因素的综合影响, 过程复杂, 在研究方法和技术手段等方面仍有待完善. 为了进一步提高研 究结果的可靠性和合理性,本文提出以下几点展望:

1) 了解不同水动力条件 (流速、流量条件及不同扰动强度等) 对营养盐存在形态、藻类吸附营养盐离子 和悬浮物的程度、速率的影响, 对于准确把握水体富营养化状态十分关键, 因此需要深化相关的机理研究.

2) 藻类受水动力条件影响的滞后性在水体富营养化的生成与发展过程中具有十分重要的作用, 弄清这 种滞后规律能更好地预测预报水华暴发的持续时间和影响范围,为水生态预警服务.

3) 水动力因子对水华藻类的影响存在一个临界值, 且不同藻类的临界值不同, 同时这个临界值也受水 体营养程度等因素的影响, 具有高度的复杂性和不确定性. 为了解决上述问题, 需要以水动力学模型为基 础, 耦合生态模型、系统动力学理论及智能算法等, 由此来精确模拟水动力条件对水体富营养化的影响, 这 将成为今后发展的一个主要方向.

\section{4 参考文献}

[ 1 ] Marshall HG, Burchardt L. Phytoplankton composition within the tidal freshwater region of the James River, Virginia. Proceedings of the Biological Society of Washington, 1998, 111: 720-730.

[ 2 ] Ha K, Cho EA, Kim HW et al. Microsystis bloom formation in the lower Nakong River, South Korea: importance of hydrodynamics and nutrient loading. Marine and Freshwater Research, 1999, 50 : 89-94.

[ 3 ] Lung WS, Paerl HW. Modeling blue-green algal blooms in the lower Neuse River. Water Research, 1988, 22 : 895-905.

[ 4 ] Steinberg C, Hartmann H. Planktonic bloom forming cyanobacteria and the eutrophication of lakes and rivers. Freshwater Biology, 1988, 20 : 279-287.

[ 5 ] Eldridge M, Sieracki ME. Biological and hydrodynamic regulation of the microbial food web in a periodically mixed estuary. Limnology and Oceanography, 1993, 38: 1666-1679.

[6] 曾 勇,杨志峰. 城市湖泊水华预警模型研究——以北京“六海”为例. 水科学进展,2007,18(1):79-85. 
[ 7 ] 王丽燕,张永春,蔡金傍. 水动力条件对藻华的影响. 水科学与工程技术,2008,(增刊):61-62.

[8] 赵 颖,张永春. 流速与温度的交互作用对铜绿微囊藻生长的影响. 江苏环境科技,2008,21(1):23-26.

[9] 李 林,朱 伟,罗永刚. 钲、镁离子在水流作用下对铜绿微囊藻生长的影响. 环境科学与技术, 2012,35(50): $9-13$.

[10］曹巧丽. 水动力条件下蓝藻水华生消的模拟实验研究与探讨. 灾害与防治工程,2008,(1):67-71.

[11] 任 健,蒋名淑,商兆堂等. 太湖蓝藻暴发的气象条件研究.气象科学,2000,28(2):221-226.

[12] 高吴东, 邓忠伟, 孙万龙等. 烟台四十里湾赤潮发生与生态环境污染研究. 中国环境监测, 2011,27(2):50-55.

[13] Acuna V, Vilches C, Giorgi A. As productive and slow as a stream can be the metabolism of a Pampean stream. Journal of the North American Benthological Society, 2011, 30(1) : 71-83.

[14] Mitrovic SM, Lorraine H, Forugh D. Use of flow management to mitigate cyanobacterial blooms in the Lower Darling River, Australia. Journal of Plankton Research, 2011, 33(2) : 229-241.

[15] Finlay JC, Power ME, Cabana G. Effects of water velocity on algal carbon isotope ratios: Implications for river food web studies. Limnology and Oceanography, 1999, 44(5): 1198-1203.

[16] Koch EW. The effect of water flow on photosynthetic processes of the alga Ulva lactuca L. Hydrobiologia, 1993, 260/261 : $457-462$.

[17] Sherman BS, Webster IT, Jones GJ et al. Transitions between Aulacoseira and Anabaena dominance in a turbid river weir pool. Limnology and Oceanography, 1998, 43: 1902-1915.

[18] Mcintire CD, Garrison RL, Phinney HK et al. Primary production in laboratory streams. Limnology and Oceanography, 1964, 9 (1): 92-102.

[19] Mitrovic SM, Oliver RL, Rees C et al. Critical flow velocities for the growth and dominance of Anabaena circinalis in some turbid freshwater rivers. Freshwater Biology, 2003, 48: 164-174.

[20] 吴晓辉,李其军. 水动力条件对藻类影响的研究进展.生态环境学报,2010,19(7) :1732-1738.

[21］王 华,逢 勇. 藻类生长的水动力学因素影响与数值仿真. 环境科学,2008,29(4):884-889.

[22] Long TY, Wu L, Meng GH et al. Numerical simulation for impacts of hydrodynamic conditions on algae growth in Chongqing Section of Jialing River, China. Ecological Modelling, 2011, 222 : 112-119.

[23] Olivier DA, Scheibling RE. Effect of wave exposure on morphology, attachment strength and survival of the invasive green alga Codium fragile ssp. tomentosoides. Journal of Experimental Marine Biology and Ecology, 2007, 351: 129-142.

[24] 张毅敏,张永春,张龙江等. 湖泊水动力对蓝藻生长的影响. 中国环境科学, 2007,27(5): 707-711.

[25] 王婷婷, 朱 伟,李 林. 不同温度下水流对铜绿微囊藻生长的影响模拟. 湖泊科学,2010,22(4):563-568.

[26] 金相灿,李兆春,郑朔方等. 铜绿微囊藻生长特性研究. 环境科学研究,2004,17:52-54.

[27] 王红萍,夏 军,谢 平等. 汉江水华水文因素作用机理一一基于藻类生长动力学的研究. 长江流域资源与环境, 2004,13 (3) :282-285.

[28] 黄 程,钟成华,邓春光等. 三峡水库蓄水初期大宁河回水区流速与藻类生长关系的初步研究. 农业环境科学学 报,2006,25(2) :453-457.

[29］李锦秀,杜 斌,孙以三. 水动力条件对富营养化影响规律探讨. 水利水电技术,2005,36(5):15-18.

[30] Huang JC, Gao JF, Hormann G. Hydrodynamic-phytoplankton model for short-term forecasts of phytoplankton in Lake Taihu, China. Limnologica, 2012, 42 : 7-18.

[31] Jeong KS, Kim DK, Joo GJ. Delayed influence of dam storage and discharge on the determination of seasonal proliferations of Microcystis aeruginosa and Stephanodiscus hantzschii in a regulated river system of the lower Nakdong River( South Korea). Water Reseach, 2007, 41: 1269-1279.

[32] 林卫青, 卢士强,陈义中. 应用生态动力学模型评价上海淀山湖富营养化控制方案. 上海环境科学, 2010,29(1): $1-10$.

[33] 龙天渝,刘腊美,郭蔚华等. 流量对三峡库区嘉陵江重庆主城段藻类生长的影响. 环境科学研究,2008,21 (4)： 104-108.

[34] Acs E, Kiss KT. Effects of the water discharge on periphyton abundance and diversity in a large river (River Danube, Hungary). Hydrobiologia, 1993, 249 : 125-133.

[35] 谢 平,夏 军,窦 明等. 南水北调中线工程对汉江中下游水华的影响及对策研究一一汉江水华发生的关键因 子分析. 自然资源学报,2004,19(4):418-422. 
[36] Mitrovic SM, Chessman BC, Davie A et al. Development of blooms of Cyclotella meneghiniana and Nitzschia spp. (Bacillariophyceae) in a shallow river and estimation of effective suppression flows. Hydrobiologia, 2008, 596: 173-185.

[37] Reynolds CS. The ecology of the planktonic blue-green algae in the North Shropshire meres, England. Field Study, 1971, 3: 409-432.

[38 ] Yamamoto T, Hashimoto T, Tarutani K et al. Effects of winds, tides and river water runoff on the formation and disappearance of the Alexandrium tamarense bloom in Hiroshima Bay, Japan. Harmful Algae, 2002, 1(3) : 301-312.

[39] Kriss RI, Raul P, Aud L et al. Effects of small-scale turbulence on lower trophic levels under different nutrient conditions. Jouranal of Plankton Reseach, 2010, 32(2) : 197-208.

[40] 蔡卓平, 段璐洋, 肖 群等. 风浪扰动促进中肋骨条藻和球形棕囊藻增殖的模拟研究. 海洋环境科学, 2011,30 (4): 473-476.

[41] 高永霞,孙小静,张战平等. 风浪扰动引起湖泊磷形态变化的模拟试验研究. 水科学进展, 2007,18(5): 668-673.

[42] Richmond A, Becker EW. Technological aspects of mass cultivation-A general outline. Boca Raton: CRC Press, 1986: 245-263.

[43] Marta E, Miquel A, Celia M. Effects of turbulence on the composition of phytoplankton assemblages in marine microcosms. Marine Ecology Progress Series, 1987, 38: 267-281.

[44] Webster IT. Effect of wind on the distribution of phytoplankton cells in lakes. Limnology and Oceanography, 1990,35 (5) : 989-1001.

[45] 朱永春,蔡启铭. 风场对藻类在太湖中迁移影响的动力学研究. 湖泊科学, 1997,9(2) : 152-158.

[46] 任 健, 商兆堂,蒋名淑等. 2007 年太湖蓝藻暴发的气象条件分析. 安徽农业科学, 2008,36(27):11874-11875.

[47] 李冬梅,高永利,田 甜等. 水体扰动对多种赤潮藻生长的影响. 热带海洋学报,2010,29(6):65-70.

[48] 颜润润,逢 勇, 王 珂等. 不同培养条件下扰动对两种淡水藻生长的影响. 环境科学与技术, 2007,30(3):10-13.

[49] Mischke U, Brigitte N. Equilibrium phase conditions in shallow German lakes: How Cyanoprokaryota species establish a steady state phase in late summer. Hydrobiologia, 2003, 502: 123-132.

[50] 颜润润, 逢 勇, 陈晓峰等. 不同风等级扰动对贫富营养下铜绿微囊藻生长的影响. 环境科学, 2008, 29(10): 2749-2753.

[51] Li Z, Wang S, Guo JS et al. Responses of phytoplankton diversity to physical disturbance under manual operation in a large reservoir, China. Hydrobiologia, 2012, 684: 45-56.

[52] 王云中, 杨成建, 陈兴都等. 不同水动力条件对景观水体富营养化模拟过程中藻类演替的影响. 环境监测管理与技 术, $2011, \mathbf{2 3}(2): 23-27$.

[53 ] Midhat MH, Amit K, Carole AL. The effect of small-scale fluid motion on the green alga Scenedesmus quadricauda. Hydrobiologia, 1998, 364: 225-235.

[54] 秦伯强,胡维平,陈伟民等. 太湖梅梁湾水动力及相关过程的研究. 湖泊科学, 2000,12(4):327-334.

[55] 陈伟民,陈宇炜,秦伯强等. 模拟水动力对湖泊生物群落演替的实验. 湖泊科学, 2000,12(4):343-352.

[56] 逢 勇, 李一平, 罗潋葱. 水动力条件下太湖透明度模拟研究. 中国科学: D 辑: 地球科学, 2005, 35 (增刊 II ): $145-156$.

[57] 彭进平, 逢 勇, 李一平等. 水动力条件对湖泊水体磷素质量浓度的影响. 生态环境, 2003,12(4):388-392.

[58] Helle P, Willern S, Bo BJ. Diffusive boundary layers of the colony-forming plankton alga Phaeocystis sp. - Implications for nutrient uptake and cellular growth. Limnology and Oceanography, 1999, 44(8): 1959-1967.

[59] 颜润润,逢 勇,赵 伟等. 环流型水域水动力对藻类生长的影响. 中国环境科学,2008,28(9):813-817.

[60 ] Hernandez I, Peralta G, PerezLlorens JL et al. Biomass and dynamics of growth of Ulva species in Palmones river estuary. Journal of Phycology, 1997, 33(5) : 764-772.

[61] Dodds WK, Smith VH, Lohman K. Nitrogen and phosphorus relationships to benthic algal biomass in temperate streams. Canadian Journal of Fisheries and Aquatic Sciences, 2002, 59(5) : 865-874. 